\title{
Interpretasi Struktur Bawah Permukaan Untuk Mengetahui Keberadaan Sumber Mata Air Di Daerah Jaboi Sabang Dengan Menggunakan Data Geolistrik Konfigurasi Schlumberger
}

\author{
Junelwan $^{1}$, Diyan Partiningtyas ${ }^{1}$, purwantiningsih ${ }^{1}$, febria anita ${ }^{\mathbf{1}}$ \\ ${ }^{1}$ Program Studi Fisika, Fakultas Teknik dan Sains, Universitas Nasional, Jakarta \\ Email: diane.tyas@gmail.com
}

\begin{abstract}
ABSTRAK. Survei geolistrik telah dilakukan di daerah Jaboi Sabang untuk mendapatkan resistivitas struktur permukaan dengan menggunakan metode Schlumberger sounding geolistrik. 4 (empat) elektroda diinjeksikan ke dalam tanah di mana resistivitas diukur menggunakan Nainura NRD 2.2 resistivity meter. Data yang didapatkan dianalisisa dengan software IXID v2. Hasil menunjukkan bahwa akuifer yang ditemukan dari model ini cukup baik untuk eksplorasi mendapatkan air bersih pada kedalaman 1,5-6,4 meteran. Nilai resistivitas pada lapisan ini berkisar 35,4 - 41,4 ohm meter yang sesuai dengan resistivitas air.
\end{abstract}

Kata Kunci: Akuifer, Resistivitas, Geolistrik, Schlumberger

\begin{abstract}
Geoelectric survey has been carried out in the area of Jaboi Sabang to obtain the resistivity of surface structure using Schlumberger geoelectrical soundings method. 4 electrodes were injected into the ground where the resistivity is measured using Nainura NRD 2.2 resistivity meter. Data collected were analysed using IXID v2 software. The results show that the acquifier found from this model is good enough to be explored for getting clean water at the depth of 1.5 to 6.4 meter. The value of resistivity in this layer ranges from 35.4 to $41.4 \mathrm{ohm}$ meter that match with the resistivity of water.
\end{abstract}

Keywords: Acquifier, Resistivity, Geoelectric, Schlumberger

\section{PENDAHULUAN}

Air merupakan sumberdaya alam yang mutlak dibutuhkan oleh setiap makhluk hidup, sehingga keberadaannya baik secara kuantitas perlu dikelola dengan baik dan berwawasan lingkungan. Hal ini dilakukan agar sumberdaya air ini dapat dimanfaatkan untuk memenuhi kebutuhan manusia baik secara langsung sebagai air baku untuk air minum, memasak membersihkan maupun yang secara tidak langsung, seperti untuk kebutuhan lahan pertanian (sawah atau kebun) demi mencapai kesejahteraan hidup yang lebih baik. Kandungan air dibumi sangat melimpah, jumlah seluruhnya mencapai 1.400 .000 .000 , terdiri dari sekitar 97\% air laut (air asin) yang dapat dimanfaatkan secara langsung dan tidak langsung dalam kehidupan manusia. Hanya 3\% sisanya yang berupa air tawar, yang meliputi $2 \%$ berupa gunung-gunung es di kedua kutub bumi. Selebihnya hanya sekitar $0,75 \%$ merupakan air tawar yang mendukung kehidupan makhluk hidup didarat, di danau, sungai dan di dalam tanah. Air tawar berasal dari siklus air (daur hidrologi) secara alami dan prosesnya panjang sehingga untuk mendapatkan air tawar yang sangat diperlukan manusia tersebut tidaklah mudah.

Pemakaian air semakin meningkat seiring dengan laju pertambahan penduduk. Oleh karena itu, maka perlu mengadakan penafsiran, perencanaan dan pengembangan yang tepat, hemat dalam pemakaian air dan melindungi sumber yang ada demi kelestarian sumberdaya alam tersebut. Persediaan sumber air di desa Jaboi secara praktis sangat terbatas, sehingga diperlukan usaha untuk memperolehnya. Keadaan ini mendorong pencarian dan pemanfaatan air tanah semakin intensif. Namun karena keterdapatan dan potensinya di dalam tanah tidak merata di semua tempat, maka diperlukan penyelidikan yang terarah sesuai dengan kaidah-kaidah yang berlaku dalam pengetahuan geologi dan hidrogeologi guna memperoleh data yang tepat dan akurat. 
Sumber air tanah didapat dengan melakukan pengeboran pada kedalaman tertentu. Sebelum melakukan pengeboran, lebih baik terlebih dahulu dilakukan survey dengan menggunakan metoda geolistrik tahanan jenis (resistivity), agar pengeboran tidak sia-sia. Metoda geolistrik tahanan jenis adalah salah satu metoda geofisika yang bisa digunakan memetakan resistivitas bawah permukaan. Hal ini dimungkinkan karena lapisan tanah dan batuan yang terisi air sangat mudah mengalirkan arus listrik atau bersifat konduktif. Lapisan tanah konduktif seperti ini biasanya memiliki harga resistivitas tertentu. Dengan menampilkan penampang resistivitas bawah permukaan hasil pengukuran geolistrik metoda resistivity maka dapat diprediksikan lapisan-lapisan tanah atau batuan yang tersaturasi air, sehingga dapat memprediksi lokasi dan kedalaman tempat lapisan tanah yang mengandung air tawar yang baik didaerah tersebut.

\section{METODE DAN BAHAN}

Penelitian sudah dilakukan di lokasi Desa Jaboi Sabang, yang dibagi dalam dua tahap:

- Tahap pertama, penelitian dilapangan dari tanggal 22 Februari 2013 di desa Jaboi, Sabang

- Tahap kedua, pengolahan data dari tanggal 15 Maret s/d 15 Desember 2013 di Laboratorium Jurusan Fisika, Fakultas Teknik dan Sains, Universitas Nasional.

Adapun alat dan bahan yang digunakan dalam penelitian ini ada dua bagian:

- Alat dan Bahan Teknik Pengukuran Lapangan

TABEL 1. Alat dan Bahan Teknik Pengukuran Lapangan

\begin{tabular}{|c|c|c|}
\hline No. & Nama Alat dan Bahan & Jumlah \\
\hline 1 & Resistivity Meter NANIURA NRD 2.1 & 1 SET \\
\hline 2 & Elektroda Arus & 2 Buah \\
\hline 3 & Elektroda potensial & 2 buah \\
\hline 4 & Kabel & Secukupnya \\
\hline 5 & Meteran & 1 buah \\
\hline 6 & Peta geologi & 1 buah \\
\hline 7 & GPS & 1 unit \\
\hline 8 & Palu & Secukupnya \\
\hline 9 & Alat tulis dan kalkulator & secukupnya \\
\hline
\end{tabular}

- Alat dan Bahan Teknik Pengolahan Data

TABEL 2. Alat dan Bahan Teknik Pengolahan Data

\begin{tabular}{|c|c|c|}
\hline No. & Nama Alat dan Bahan & Jumlah \\
\hline 1 & Software Aplikasi IX1Dv2 (Interplex) & 1 unit \\
\hline 2 & Komputer & 1 set \\
\hline 3 & Kalkulator (alat hitung) & 1 buah \\
\hline
\end{tabular}

\section{Prosedur Kerja}

Tahap Persiapan:

- Dilakukan survei awal di lokasi desa Jaboi, Sabang

- Dilakukan studi pustaka dan pengurusan perizinan ke pihak terkait

- Mempersiapkan desain survei (terlampir)

- Mempersiapkan peralatan

Tahap Pelaksanaan di lapangan pengukuran geolistrik dilakukan dengan menggunakan konfigurasi Schlumberger. Adapun langkah pengukurannya adalah sebagai berikut:

- Sebelum melakukan pengukuran yang perlu diperhatikan adalah letak permukaan tanah hampir rata (datar) dan diusahakan tidak terdapat benda-benda yang dapat mengganggu jalannya arus listrik.

- Baterai 12 volt dihubungkan dengan alat resistivity meter.

- Elektroda arus dan elektroda potensial dipasang dipermukaan tanah pada jarak-jarak yang telah ditentukan sesuai dengan susunan elektroda konfigurasi Schlumberger yaitu 
dengan menggunakan 4 buah elektroda pada jarak yang tertentu sepanjang garis lurus. Elektroda yang terletak di bagian luar berfungsi sebagai penerus arus listrik ke dalam tanah, sedangkan dua elektroda di bagian dalam berfungsi sebagai pengukur besarnya tegangan yang ditimbulkan sebagai akibat arus listrik yang dialirkan kedalam tanah.

- Jika terdapat rumah pemukiman, perkebunan, bangunan kantor pemerintah, maka bentangan dilebihkan 200m (diinterpolasi).

- Elektroda arus dan elektroda potensial yang telah dipasang di permukaan tanah dihubungkan dengan resistivity meter.

- Tombol "start" pada resistivity meter ditekan untuk mengirimkan arus.

- Tombol "hold" pada resistivity meter ditekan setelah besar arus (I) dan beda potensial (V) yang timbul stabil.

- Besar kuat arus dan potensial dicatat sehingga berdasarkan hukum Ohm dapat ditentukan tahanan jenis ( R ).

- Hasil pengukuran yang diperoleh dicatat pada tabel yang telah disiapkan

Prosedur kerja pengolahan data

- Data geolistrik hasil pengukuran lapangan yang telah didapatkan akan dilakukan pengolahan data dengan menggunakan software aplikasi IX1D v2.

- Dilakukan interpretasi kualitatif data geolistrik listrik berdasarkan informasi geologis daerah penelitian.

- Ditentukan lapisan akuifer (pembawa air) dari refleksi grafik hasil pengolahan data software aplikasi IX1D v2.

- Hasilnya ditampilkan dalam bentuk ketajaman citra lapisan bawah permukaan. Kemudian hasil ini diinterpretasikan dengan bantuan data geologi

Tahap Analisa dan Interpretasi

- Analisis struktur bawah permukaan, hasilnya ditampilkan dalam bentuk ketajaman citra lapisan bawah permukaan.

- Interpretasi kandungan air bawah permukaan

\section{HASIL DAN PEMBAHASAN}

Pada titik sounding 1 mulai terlihat adanya harga resistivitas yang beragam, dimana menunjukkan kemungkinan lapisan akuifer mulai dari kedalaman $4 \mathrm{~m}-65.02 \mathrm{~m}$. Pada kedalaman $4 \mathrm{~m}$ harga resistivitas menunjukkan harga atau nilai $10.172 \mathrm{ohm}$ meter. Berdasarkan peta geologi dan tabel 3 jenis batuan disini merupakan batuan pasir dengan area sesar naik yang dibawa dari lempeng batuan vulkanik (batuan pasir tufa).

Disamping itu area kelompok batuan pasiran ini diblocking (terjadi block fault) oleh batu gampingan dengan arah North-West, South-East (NW-SE) hasil dari sesar naik. Sehingga hal ini mengakibatkan terkumpulnya mata air. Untuk grafik soundingnya dapat dilihat pada gambar 1.

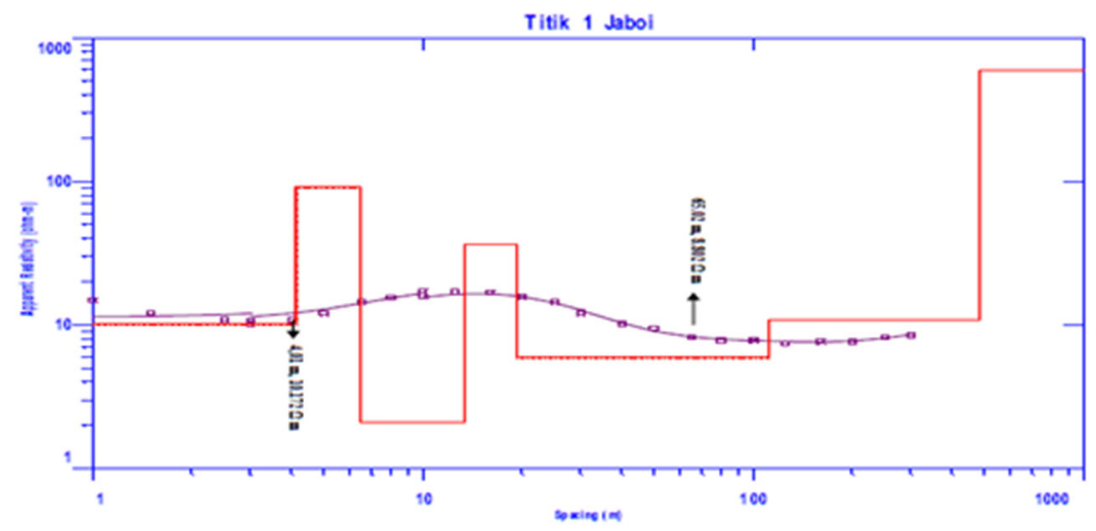

GAMBAR 1. Grafik Sounding 1 pengukuran resistivitas. 
Pada titik 2 kemungkinan akuifer diperlihatkan pada kedalaman mulai dari $24.78 \mathrm{~m}$ dengan resistivitas $10.180 \mathrm{Ohm}$ meter, hingga kedalaman $249.16 \mathrm{~m}$ dengan resistivitas $59.011 \mathrm{Ohm}$ meter. Dibawah $24.78 \mathrm{~m}$ struktur batuan bersifat impermeable memiliki porositas kecil (5 $\mathrm{m} / 4.357 \mathrm{Ohm}$ meter). Dan dapat diketahui batuan didominasi oleh tanah liat (clay) dan batuan lumpur hasil dari formasi batuan vulkanik, sehingga pada titik ini eksplorasi akuifer agak sulit dalam pelaksanaannya seperti tabel 4. Untuk grafik soundingnya dapat dilihat pada gambar 2.

TABEL 3. Model Litologi Sounding 1.

\begin{tabular}{|c|c|c|c|c|c|}
\hline No. & $\rho(\Omega m)$ & Top & Bottom & Tebal $(\mathrm{m})$ & Litologi \\
\hline 1 & 9,83 & 0 & 4,12 & 4,12 & Soil-Pasir \\
\hline 2 & 89,13 & 4,12 & 6,5 & 2,38 & Pasir \\
\hline 3 & 2,07 & 6,5 & 13,3 & 6,8 & Lempung \\
\hline 4 & 36,61 & 13,3 & 19,1 & 5,8 & Gravel \\
\hline 5 & 5,81 & 19,1 & 110,3 & 91,2 & Lempung \\
\hline 6 & 10,88 & 110,3 & 476,2 & 365,9 & Gravel \\
\hline 7 & 527,27 & 476,2 & $\sim$ & $\sim$ & \\
\hline
\end{tabular}

TABEL 4. Model Litologi Sounding 2.

\begin{tabular}{|c|c|c|c|c|c|}
\hline No & $\rho(\Omega m)$ & Top & Bottom & Tebal $(\mathrm{m})$ & Litologi \\
\hline 1 & 4,65 & 0 & 5,5 & 5,5 & Clay \\
\hline 2 & 31,56 & 5,5 & 6,4 & 0,9 & Clay \\
\hline 3 & 2,86 & 6,4 & 10 & 3,6 & Clay \\
\hline 4 & 87,90 & 10 & 15,4 & 5,4 & Pasir \\
\hline 5 & 1533,21 & 15,4 & 49 & 33,6 & Tanah lepas \\
\hline 6 & 12,94 & 49 & 627,2 & 578,2 & Gravel \\
\hline 7 & 550 & 627,2 & $\sim$ & $\sim$ & \\
\hline
\end{tabular}

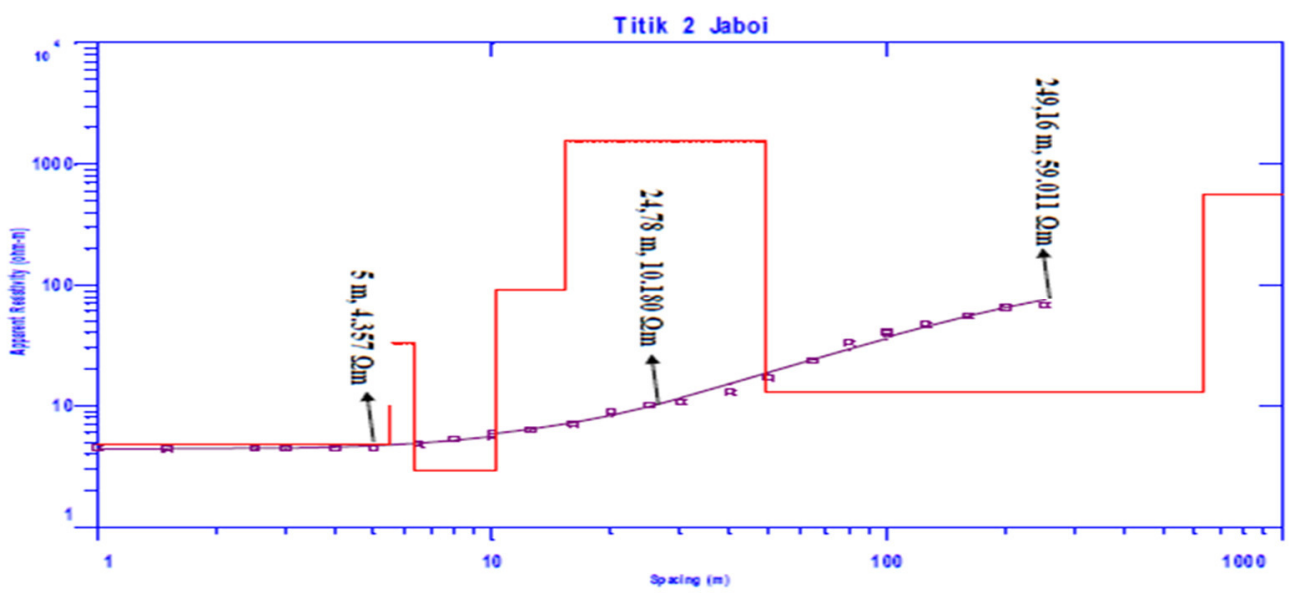

GAMBAR 2. Grafik Sounding 2 pengukuran resistivitas

Pada titik 3 memperlihatkan nilai akuifer yang cukup baik mulai dari kedalaman $1.5 \mathrm{~m}$ dengan resistivitas $36.292 \mathrm{Ohm}$ meter, kedalaman $2.51 \mathrm{~m}$ dengan resistivitas $35.355 \mathrm{Ohm}$ meter, kedalaman $5.00 \mathrm{~m}$ dengan resistivitas $41.438 \mathrm{Ohm}$ meter, dan kedalaman $6.43 \mathrm{~m}$ dengan resistivitas $42.678 \mathrm{Ohm}$ meter. Rata-rata pada area ini struktur batuan bersifat permeable dengan jenis tanah berupa pasir tufa + gamping, tanah lepas, batu apung dan coral dari formasi vulkanik seperti tabel 5. Untuk grafik soundingnya dapat dilihat pada gambar 3.

TABEL 5. Model Litologi Sounding 3

\begin{tabular}{|c|c|c|c|c|c|}
\hline No. & $\rho(\Omega m)$ & Top & Bottom & Tebal $(\mathrm{m})$ & Litologi \\
\hline 1 & 35,81 & 0 & 24,5 & 24,5 & Clay \\
\hline 2 & 92,90 & 24,50 & 26 & 1,5 & Pasir \\
\hline 3 & 125 & 26 & 35,7 & 9,7 & Pasir \\
\hline 4 & 78,92 & 35,7 & 40,9 & 5,2 & Pasir \\
\hline 5 & 125,55 & 40,9 & 54,1 & 13,2 & Pasir \\
\hline 6 & 31,10 & 54,1 & 548,4 & 494,3 & Clay \\
\hline 7 & 585,06 & 548,40 & $\sim$ & & \\
\hline
\end{tabular}




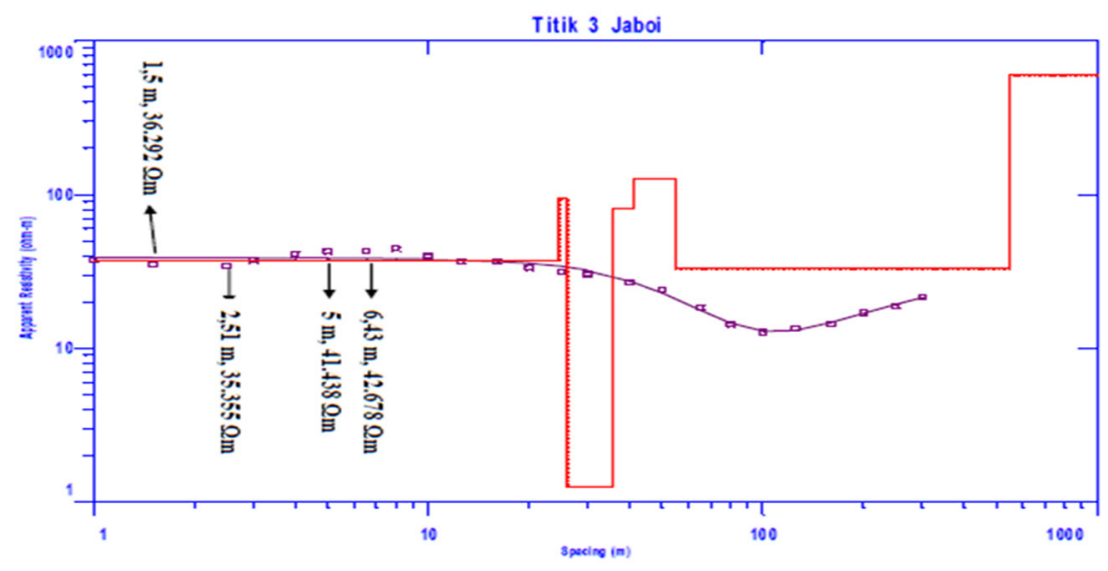

GAMBAR 3. Grafik Sounding 3 pengukuran resistivitas

\section{KESIMPULAN}

Setalah dilakukan akuisisi dan interpretasi data lapangan pada semua titik sounding, maka dapat disimpulkan bahwa kedalaman akuifer pada titik sounding 1 berada pada kedalaman antara 4 hingga 65.02 meter. Kedalaman akuifer pada titik sounding 2 berada pada kedalaman antara 24.78 hingga 249.16 meter. Kedalaman akuifer pada titik sounding 3 berada pada kedalaman antara 1.5 meter hingga 6.43 meter sampai tak hingga. Nilai akuifer terlihat cukup baik. Jadi kedalaman akuifer di daerah Jaboi Sabang yaitu berada pada kedalaman antara 1.5 meter sampai 249.16 meter.

\section{DAFTAR PUSTAKA}

[1]. Dobrin, B.M., and Savit, C.H., 1988, Introduction to Geophysical Prospecting, 4Th ed., Mc Graw Hill Bool Company.

[2]. Lilik Hendrajaya, \& Arief, I., 1990. Metode Geolistrik Tahanan Jenis, Lab Fisika Bumi, Institut Teknologi Bandung, Bandung.

[3]. Muhammad Untung, dkk, 2000, Geofisika dekat permukaan, Himpunan Ahli Geofisika Indonesia, Jakarta.

[4]. Santoso Djoko, 2002 Pengantar Teknik Geofisika Penerbit ITB, Bandung tahun 2002

[5]. Soemarto, CD., 1995. Hidrologi Teknik, Erlangga, Jakarta.

[6]. Sultan, 2009. Penyelidikan Geolistrik Resistivity pada Penentuan Titik Sumur Bor untuk Pengairan di Daerah Garongkong Desa Lempang Kecamatan Tanete Riaja Baru. Jurnal Penelitian Enjiniring Vol. 12, No. 2, Universitas Hasanuddin, Makassar.

[7]. Telford, W. M., Geldart, L., P., Sheriff, R. E., and Key. D. A. 1976, Applied Geophysics. (London: Cambridge Univ. Press)

[8]. Urrilijanto, Y., 2002. Survey Geolistrik dalam Rangka Pengeboran Air Bawah Tanah di Lhok Nga Kabupaten Aceh Besar, Laporan Penyelidikan Dinas Pertambangan dan Energi Nanggroe Aceh Darussalam.

[9]. Yona Akbar, dkk., 2008. Laporan Field Camp Teknik Geofisika, Institut Teknologi Bandung, Bandung. 